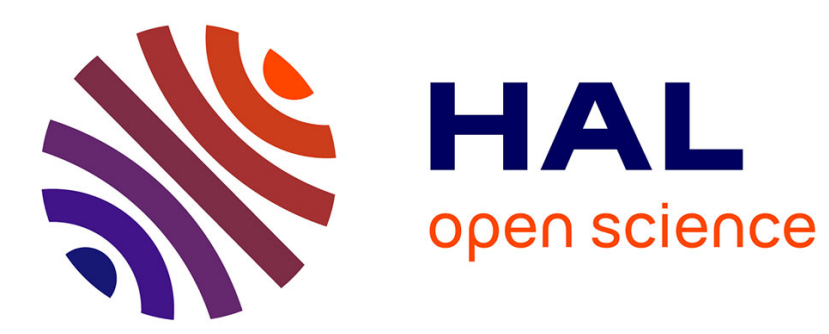

\title{
Which contextual and sociocultural information predict irony perception?
}

Elora Rivière, Maud Champagne-Lavau

\section{To cite this version:}

Elora Rivière, Maud Champagne-Lavau. Which contextual and sociocultural information predict irony perception?. Discourse Processes, 2020, 57, pp.259-277. 10.1080/0163853X.2019.1637204 . hal02189429

\section{HAL Id: hal-02189429 \\ https://hal.science/hal-02189429}

Submitted on 17 Apr 2020

HAL is a multi-disciplinary open access archive for the deposit and dissemination of scientific research documents, whether they are published or not. The documents may come from teaching and research institutions in France or abroad, or from public or private research centers.
L'archive ouverte pluridisciplinaire HAL, est destinée au dépôt et à la diffusion de documents scientifiques de niveau recherche, publiés ou non, émanant des établissements d'enseignement et de recherche français ou étrangers, des laboratoires publics ou privés. 


\section{Which contextual and sociocultural information predict irony perception?}

Elora Rivière, Maud Champagne-Lavau

Aix Marseille Univ, CNRS, LPL, Aix-en-Provence, France

Manuscript accepted for publication in Discourse Processes

Rivière, E. \& Champagne-Lavau. M (2020). Which contextual and sociocultural information predict irony perception? Discourse Processes, 57, 259-277 DOI : 10.1080/0163853X.2019.1637204.

Corresponding author: Elora Rivière,

Aix-Marseille Université

LPL, CNRS UMR 7309

5 Av. Pasteur

B.P. 80975

13604 Aix-en-Provence, France

Phone: (33) 0413552733

email: elora.riviere@1pl-aix.fr 


\begin{abstract}
The present study in French sought to investigate which factors predict irony perception most efficiently. An experiment was developed following three steps. The first two steps focused on the creation of stimuli to be evaluated in the third one. In the last step, participants, whose sociocultural characteristics (gender, age and level of education) were taken into account as factors, evaluated utterances according to their level of irony and the presence of contextual factors (i.e., allusion to a failed expectancy, negative tension and presence of a victim). The absence or presence of a lexical marker in the utterances was also a controlled factor. The main results revealed contextual factors as the strongest predictors of irony perception but also pointed out the not inconsiderable role played by the sociocultural factors (gender and level of education) of the participants.
\end{abstract}

\title{
Keywords
}

Irony, sociocultural factors, gender, contextual factors, lexical marker, Constraints Satisfaction model, allusion to a failed expectancy 


\section{Introduction}

There is always a risk that people will fail to understand irony. Even so, verbal irony is a form of non-literal language - as is metaphor or indirect request - that represents $8 \%$ of our turns of speech (Gibbs, 2000). Verbal irony can be defined as a type of utterance in which what is stated is different from or, in some cases, contrary to what the speaker means (Gibbs, 1986). For irony to be understood, the listener is required to differentiate what the speaker says from what he/she means using the relevant contextual information (Grice, 1975; Searle, 1978).

Research on irony processing has produced varied results. Some results based on reading time have shown that the ironic meaning of an utterance is longer to process than either its metaphoric one (Colston \& Gibbs, 2002) or its literal one (Champagne, Jean-Louis, \& Joanette, 2006; Colston \& Gibbs, 2002; Deliens, Antoniou, Clin, \& Kissine, 2017; Dews \& Winner, 1999). These results argue in favor of models that support an obligatory first literal interpretation as the Standard Pragmatic Model (Grice, 1975) or an obligatory first salient interpretation (Giora \& Fein, 1999). Other studies indicate that the ironic meaning of an utterance is processed just as fast as its literal counterpart (Gibbs, 1986), which supports a Direct Access Model (Gibbs, 1986) arguing that the non-literal meaning can be accessed directly, without the need of a first literal interpretation. The Constraints Satisfaction Model helps us to understand the heterogeneity of these results. In this probabilistic model, the information from various sources (e.g., context, utterance, interlocutors) is integrated rapidly and in parallel in order to construct a coherent interpretation that better fits the available information than an alternative interpretation would have done (Gibbs, 2001; Pexman, 2008). Indeed, a number of studies based on analyses of on-line data have shown the parallel influence of various types of factors (Akimoto, Miyazawa, \& Muramoto, 2012; Katz \& Ferretti, 2001; Pexman, Ferretti, \& Katz, 2000; Spotorno \& Noveck, 2014). Since these factors have a constraining effect on the interpretation, they are called constraints. According to this model, no information (i.e., constraints) or set of information is necessary, but constraints or sets of constraints could be sufficient to imply an ironic meaning. As the Constraints Satisfaction Model suggests that ironic interpretation is considered as soon as there is sufficient evidence that it might be supported (Pexman, 2008), the variability in the previous results could be explained by differences in the availability and strength of constraints inducing literal and non-literal interpretations. Thus, a challenge is to identify the combination of constraints which a listener is sensitive to when interpreting an utterance as 


\section{VERSION AUTEUR}

ironic and to quantify the relative strength of these constraints in various situational contexts. The present study focused on the impact of several kinds of factors on irony comprehension within the Constraints Satisfaction Model, as this model has the advantage of making it possible to study various factors in interaction. Below we review different types of constraints likely to account for irony interpretation.

Different factors, which can be incorporated into the Constraints Satisfaction model, have been put forward by more recent theories (e.g., Allusional Pretense Theory of Discourse Irony (Kumon-Nakamura, Glucksberg, \& Brown, 1995), Implicit Display Theory of Verbal Irony (Utsumi, 2000)) as cues to irony interpretation (e.g., allusion to a failed expectancy, negative tension, presence of a victim, pragmatic insincerity, gender, occupation, level of education, age, presence of lexical marker). Allusion to a failed expectancy (Campbell \& Katz, 2012; Kumon-Nakamura et al., 1995; Utsumi, 2000) - also referred as contextual incongruity (Champagne-Lavau, Charest, Anselmo, Rodriguez, \& Blouin, 2012; Deliens, Antoniou, Clin, Ostashchenko, \& Kissine, 2018; Gerrig \& Goldvarg, 2000; Ivanko \& Pexman, 2003), situational disparity (Voyer, Thibodeau, \& Delong, 2014), or contrast (Colston, 2002; Colston \& O'Brien, 2000; Colston \& O’Brien, 2000) - is defined as “an allusion to some prediction, expectation, preference, or norms that have been violated" (Kumon-Nakamura et al. (1995, p5), or more simply, as a contrast between expectation and reality. In the following example from Utsumi (2000), a mother's sentence "This room is totally clean!" is ironic, alluding to the mother's failed expectancy to find a clean room.

A mother asked her son to clean up his messy room, but he was lost in a comic book. After a while, she discovered that his room was still messy, and said to her son:

(1) This room is totally clean!

Kumon-Nakamura et al., (1995) asked participants to agree or disagree with statements corresponding to allusions to a failed expectancy of an ironic utterance and have shown that in ironic stories, allusions to a failed expectancy are perceived $97 \%$ of the time. In a similar experiment, Colston \& Gibbs (2002) revealed that speakers are more often evaluated as making reference to their previous beliefs when producing an ironic utterance than when producing a metaphoric one. Moreover, Colston (2000) and Kumon-Nakamura et al., (1995) observed that when stories contain an allusion to a failed expectancy, positive evaluation (e.g., "this is great") of a negative outcome and negative evaluation (e.g., "this sucks") of a positive outcome were judged as more ironic than their literal counterparts. Other studies have shown that a larger contrast between expectations and reality increases the recognition 


\section{VERSION AUTEUR}

of sarcasm and irony (Champagne-Lavau, Charest, et al., 2012; Champagne-Lavau, Cordonier, Bellmann, \& Fossard, 2018; Colston, 2002; Colston \& O'Brien, 2000; Deliens et al., 2018; Gerrig \& Goldvarg, 2000; Ivanko \& Pexman, 2003; Rivière, Klein, \& ChampagneLavau, 2018; Voyer et al., 2014; Woodland \& Voyer, 2011) while the absence of incongruity between expectation and reality leads to interpreting the target utterance as sincere.

According to the Implicit Display Theory (Utsumi, 2000), the speaker must make an allusion to a failed expectancy to implicitly display an ironic environment. Utsumi (2000) considers another factor called negative tension, saying that the speaker experiences a negative emotional attitude (e.g., disappointment, anger, reproach, envy) concerning the incongruity between his/her expectation and reality. If we look at the previous example, in (1) the mother expresses a negative attitude about the failure of her expectancy to find a clean room.

Verbal irony, more precisely a subtype called sarcasm, can also involve a victim. Victims of irony are people or groups of people who can be identified as being mocked by the ironic statement (Kreuz \& Glucksberg, 1989; Lee \& Katz, 1998) or being held responsible for the failure of the expectancy (Utsumi, 2000). The presence of a victim can contribute to irony perception (Utsumi, 2000) and increase the degree of perceived sarcasm of positive and negative remarks (Kreuz \& Glucksberg, 1989).

In addition to the aforementioned factor of allusion to a failed expectancy, the Allusional Pretense Theory of Discourse Irony (Kumon-Nakamura et al., 1995) affirms that for an utterance to be perceived as ironic, the factor of pragmatic insincerity - relying on language use (Campbell \& Katz, 2012) and not on truth value of the utterance (Grice, 1975, 1978 ; Searle, 1978) - is also necessary. According to Kumon-Nakamura et al., (1995), pragmatic insincerity can be defined as the violation of one or more than one of the felicity conditions. They put forward that only $4 \%$ of the speakers of ironic utterances were perceived as sincere (Kumon-Nakamura et al., 1995). However, the necessity of this factor is disputed by Colston (2000) who found that a pragmatically sincere utterance may be understood as more ironic than a sincere comment. Moreover, Campbell \& Katz (2012), who studied this factor and the other factors reported above in the framework of the Constraints Satisfaction Model, proved that even if the four factors - allusion to a failed expectancy, negative tension, presence of a victim and pragmatic insincerity - are predictors of sarcasm, pragmatic insincerity is the weakest one. They have also found that some utterances which were highly evaluated as sarcastic were judged as having a low level of pragmatic constraints including pragmatic insincerity (Campbell \& Katz, 2012). They concluded, in accordance with the Constraints 
Satisfaction model, that none of these factors are necessary to understand irony (Campbell \& Katz, 2012). Following results from Colston (2000) and Campbell \& Katz (2012), we focused on allusion to a failed expectancy, negative tension and presence of a victim and excluded pragmatic insincerity. Since these characteristics are present in the context, we called these factors pragmatic constraints.

We also took into account another factor, which we named linguistic constraint (i.e., lexical markers) likely to play a role in irony processing and to interact with the other pragmatic constraints. Linguistic constraint is a characteristic of the ironic utterance itself. The results concerning the role played by lexical markers do not lead to consensus. Utsumi (2000) suggests that the negative tension constraint, i.e. the negative attitude concerning the failed expectancy, can be expressed indirectly via different cues including verbal cues like lexical markers (e.g. an adverb). According to Attardo (2000), the presence of lexical markers (e.g., What beautiful weather; You are really nice) alerts the listener to the fact that the utterance is ironic. Lexical markers thus facilitate irony recognition (Attardo, 2000) and comprehension (Attardo, 2000; Burgers, van Mulken, \& Schellens, 2012) as well as decreasing its perceived complexity (Burgers et al., 2012). However, lexical markers are not predictors of the sarcastic perception of an utterance (Kreuz \& Caucci, 2007) and their suppression does not influence the presence of irony (Attardo, Eisterhold, Hay, \& Poggi, 2003). On the contrary, Kunneman, Liebrecht, van Mulken, \& van den Bosch (2015) showed that intensifier-lexical markers are predictors of sarcasm. Hancock (2004) also demonstrated that one out of five ironic utterances contain an amplifier lexical marker.

Research has proven that the characteristics of the context (i.e., pragmatic constraints) and the characteristic of the ironic utterance itself (i.e., linguistic constraint) may play a role in irony perception, but Colston (2005) also suggested that social and cultural factors may have an even greater impact on the processing of non-literal language. Various sociocultural factors including the interlocutors' social rank (Gucman, 2016; Holtgraves, 1994, 1997a), the speakers' occupations (Katz \& Pexman, 1997; Pexman et al., 2000), their level of education (Champagne et al., 2006; Champagne-Lavau, Monetta, \& Moreau, 2012), the culture of their country (Holtgraves, 1997b) or region (Dress, Kreuz, Link, \& Caucci, 2008) influence the perception and production of non-literal language. Moreover some studies have shown that some of these sociocultural factors such as occupation (Pexman et al., 2000) or gender (Katz et al., 2001) are integrated early on in irony processing. Amongst these factors, gender has received particular attention. In studies examining the gender of the producers, some authors have reported that men tend to use sarcastic remarks (Gibbs, 2000; Rockwell \& Theriot, 


\section{VERSION AUTEUR}

2001) and tend to be chosen as the speaker of ironic utterances (Colston \& Lee, 2004) more often than women. When participants have to evaluate their production, men have a tendency to auto-evaluate themselves as more ironic than women (Bowes \& Katz, 2011; Dress et al., 2008; Milanowicz, 2013). However, in some context completion tasks, women have been seen to produce irony as often as men (Bowes \& Katz, 2011; Dress et al., 2008). Moreover, when male and female characters are depicted making sarcastic comments, participants do not necessarily judge male characters as being more sarcastic than female ones (Colston \& Lee, 2004). Colston \& Lee (2004) also remarked that the pragmatic functions of verbal irony better fit female discourse goals than male ones. When looking at the perceivers' gender, Woodland \& Voyer (2011) did not find any difference between men and women when they asked them to judge if a tone of voice was sarcastic. Nevertheless, Holtgraves (1991) highlighted that women are more likely than men to interpret statements as being indirect. Taken as a whole, these results lead us to think that there is insufficient agreement concerning any advantage of men or women in irony perception and production.

Thus, as there was no consensus in the literature on the impact of gender on irony comprehension and few results regarding the level of education and age of the participants, we included the sociocultural characteristics of participants who have evaluated the ironic utterances and their contexts as sociocultural constraints in the present study. In addition, since the perspective of the participants has an influence on irony judgment (Deliens et al., 2017) we took care of the one in which perspective we chose to place the participants. Deliens et al., (2017) placed participants in a third person perspective and showed that under time pressure, participants had a higher accuracy rate in an egocentric condition than in an allocentric one. Deliens et al., (2017) concluded that participants tend to start with an egocentric perspective when they have to interpret sarcasm. For this reason we decided, as recommended by Bryant (2012), to move away from third party judgments and to engage our participants in the discourse as speakers of the ironic utterances.

Most studies on irony have been carried out in English. It is well known that in some cultures, such as collectivist ones, people tend to produce and look for indirect meaning more than people in other cultures, such as individualist ones (Holtgraves, 1997b). Cross-linguistic and cross-cultural work are important because irony, as other types of non-literal language, relies on the integration of contextual factors, and people can be more or less sensitive and more or less responsive to these factors according to their culture and their language (Gudykunst, Yoon, \& Nishida, 1987; Holtgraves \& Yang, 1992; Triandis, Bontempo, Villareal, Asai, \& Lucca, 1988). For example, studies in various languages reveal different 


\section{VERSION AUTEUR}

results about the role played by lexical markers and about acoustic parameters marking sarcasm. Research on Dutch (Kunneman et al., 2015) showed that lexical markers were predictors of sarcasm, contrary to a study on English (Kreuz \& Caucci, 2007). The mean F0 that has been proven to be the most important acoustic parameter to mark sarcasm in English (Cheang \& Pell, 2011), seems to be used differently across languages (cf., Scharrer \& Christmann, 2011 for a cross-language review). Because the language of the study may impact the role played by the factors, it is crucial for languages other than English to be studied. Our study was the first to explore how a combination of different types of constraints (pragmatic, linguistic and sociocultural) affects irony perception in French.

The objective of the present study was to investigate - in French - within the Constraints Satisfaction Hypothesis, which constraints (i.e., pragmatic, linguistic and sociocultural) or set of constraints predict the interpretation of an utterance as ironic, and to quantify the relative strength of these constraints.

To complete our objective, we used the paradigm developed by Campbell \& Katz (2012) adapting the type of constraints investigated. We studied the same pragmatics constraints (allusion to a failed expectancy, negative tension and presence of a victim) except for pragmatic insincerity, but we added a linguistic constraint (i.e., lexical marker) and sociocultural constraints (i.e., age, level of education and gender of the rating participants).

We developed an experiment carried out in three steps. The first two steps were dedicated to the construction of the stimuli which were rated in the third experiment. More precisely, the first step was dedicated to the selection of target utterances that could be understood with an ironic meaning as often as with a sincere meaning. The second step was devoted to the creation of contexts that would induce an ironic or sincere comprehension of the target utterances selected in the first step. In this way, if the target utterances were rated as ironic in the third step, it has been thanks to the context information created by the producing participants. Finally, the third step was dedicated to the evaluation of the degree of irony of the target utterances and the evaluation of the presence of the three pragmatic constraints (allusion to a failed expectancy, negative tension and presence of a victim) in the target utterances and their contexts. The pragmatic constraints were in the context information produced by participants in the second step while the linguistic constraint was a characteristic of the utterance (i.e., manipulation of the absence/presence of a lexical marker in the target utterance interpretable as ironic) and the sociocultural constraints were characteristics of the participants who rated the level of irony of the target utterances. 


\section{VERSION AUTEUR}

Given previous results from the literature (Campbell \& Katz, 2012) we hypothesized that the pragmatic constraints allusion to a failed expectancy, negative tension and presence of a victim would be predictors of the utterance being judged ironic. As there is no consensus in the literature regarding the role played by the other linguistic and sociocultural constraints that we investigated, with regards to irony judgment, we had no a priori hypothesis regarding these constraints.

\section{Step 1: Selection of target utterances}

The objective of the first step was to select 40 target utterances that could be understood either ironically or sincerely, for use in the next steps.

\section{Participants}

Thirty participants (16 men and 14 women) were recruited for this step and were all native French speakers. They were aged 18-29 years old $(M=24.00 \pm 3.13)$ and had a level of education between 12 and 19 years $(M=15.40 \pm 1.75)$. The participants were students from Aix-Marseille University. They did not declare any cerebral or neurologic antecedents or psychiatric disorders.

\section{Material, task and procedure}

Sixty target utterances were created for the present study. To introduce the linguistic constraint lexical marker, $50 \%$ of the target utterances contained a lexical marker such as a pronoun or an adverb (e.g. What beautiful weather [Quel temps splendide], You are extremely generous [Tu es extrêmement généreuse]) and 50\% did not, leading to two lexical marker conditions (present, absent). Target utterances pointed either to a situation or to someone (cf. Example table 1).

Table 1. Example of target utterances in each category.

\begin{tabular}{|c|c|}
\hline Lexical marker & Target utterance \\
\hline Present & $\begin{array}{c}\text { What beautiful weather } \\
\text { [Quel temps splendide] }\end{array}$ \\
\hline Absent & $\begin{array}{c}\text { That is fast } \\
\text { [C'est rapide] }\end{array}$ \\
\hline
\end{tabular}




\section{VERSION AUTEUR}

No punctuation was used in the target utterances to let the participants free to integrate the utterances into ironic and sincere contexts that they encounter in their daily life. The absence of punctuation also allowed us to use the same target utterance for both instructions of the second step: to produce a context to induce either an ironic or a sincere interpretation of the target utterance.

The 60 target utterances were organised into four lists each with a different random order. Participants were asked to rate, on a 7-point Likert scale (1-never to 7-always) the degree to which an item is conventionally understood as sarcastic or ironic when out of context. The instructions were the same as Campbell \& Katz (2012, p.462): "Your task is to rate the statements in italics on the scale provided. The scale is a rating of how often (conventionally) the statement is used with a sarcastic or ironic meaning (stating the opposite of what the speaker intends)."

\section{Results}

The mean score for each target utterance was calculated. In keeping with our aim to select target utterances which could be understood ironically as well as sincerely, the 40 target utterances with the most mid-range results were kept (scores between 3 and 5) (c.f., annex 1 for selected target sentences). The average rating did not differ from the midpoint (3.5), $\mathrm{t}$ (39) $=1.258 ; \mathrm{p}>0.05$. This selection was made so as to obtain 20 stimuli with lexical markers and 20 stimuli without lexical markers. The average rating between the two lexical marker conditions, with a lexical marker $(M=3.73 \pm 0.43)$, without a lexical marker $(M=3.48 \pm$ $0.55)$, did not differ $(t(38)=1.604 ; p>0.05)$.

\section{Step 2: Context production}

The objective of this second step was to obtain several stories that could induce either ironic or sincere interpretations of the same target utterance. To achieve this, participants were asked to complete contexts to induce ironic or sincere interpretation of the target utterances.

\section{Participants}

Fifty-nine participants (30 women, 29 men) took part in this step. None of them had participated in the previous step. 


\section{VERSION AUTEUR}

All of them were French native speakers; none of them declared any cerebral or neurologic antecedents or psychiatric disorders. Participants were aged 19-50 years old $(M=$ 29. $75 \pm 9.32)$ and had a level of education between 11 and 20 years $(M=15.49 \pm 1.94)$. They were recruited in the local community.

\section{Material, task and procedure}

The 40 target utterances (20 with lexical markers, 20 without lexical markers) selected in the first step were embedded in minimal contexts (in bold) leading to 40 incomplete stories. Each stimulus was composed of a blank followed by a sentence allowing us to introduce the situation in which the participant is put in the perspective of the protagonist (e.g., You and Clara want to go for a picnic [Vous et Clara voulez aller pique-niquer]), followed by a second blank. Then a second sentence introduced the intervention of the participant as a speaker to an listener (e.g., You look outside and say to Clara: [Vous regardez dehors et dites à Clara :]). At the end of the minimal context, the italicized target utterance was placed in inverted commas (e.g., "What beautiful weather" ["Quel temps splendide”]). Participants were asked to fill in the blanks. 


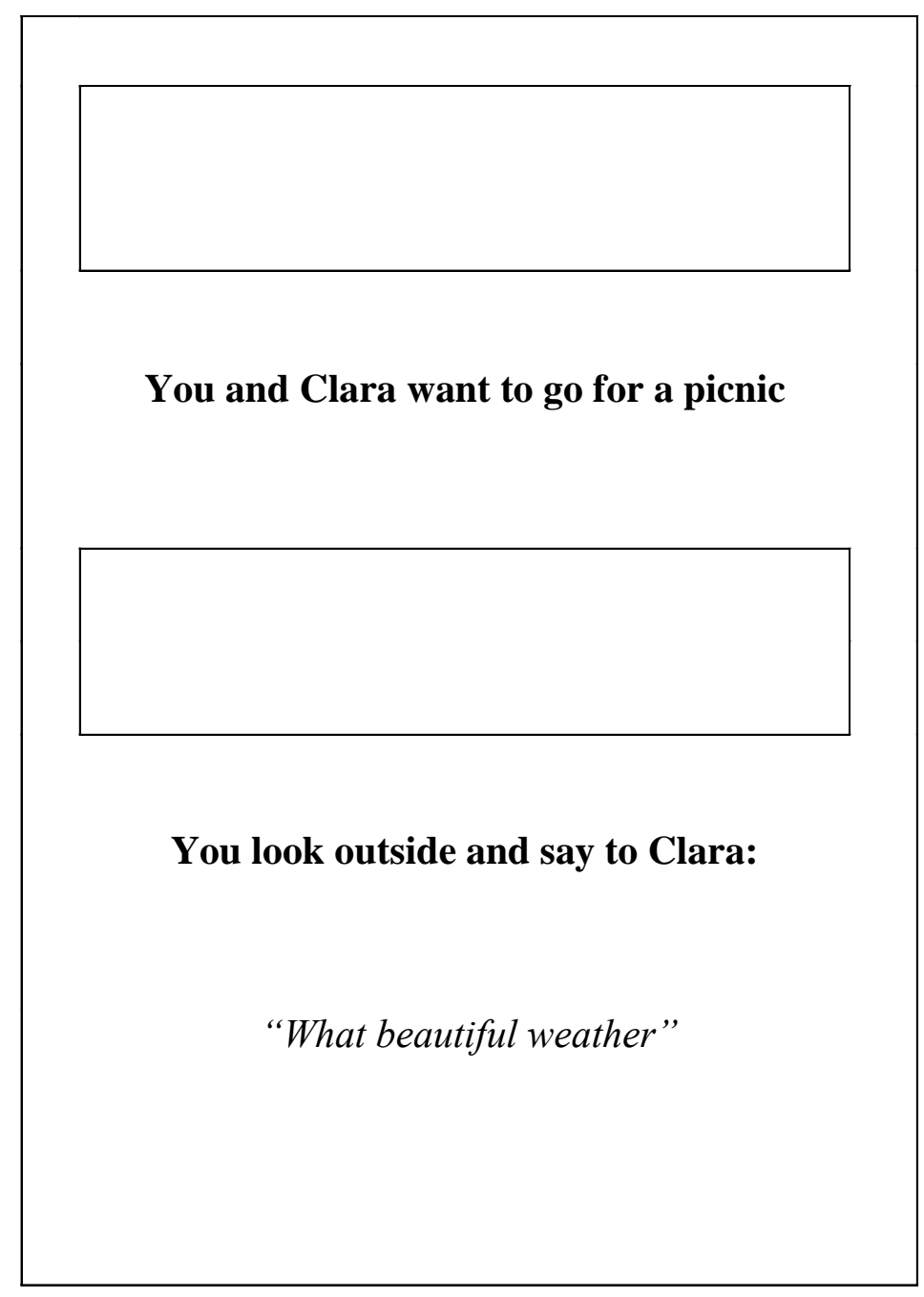

Figure 1. Example of story material.

The gender of the character listener (e.g., Clara) was controlled. Fifty percent of the stories contained a female character listener and $50 \%$ a male character listener. Eight booklets were created containing the 40 stories (20 with lexical markers, 20 without) and presented in four different random orders so that each participant received one booklet with either the sincere instruction or the ironic instruction. Each booklet contained two identical training stories.

In the ironic instruction, participants were asked to complete one or both blanks, with the amount of information considered sufficient to make the target utterance understandable as ironic.

The ironic instruction was presented as follows: "You will see some stories. A minimal context (in bold) is provided to the situation in which the target utterance (italicized) was made. You have to add some information to the context in which way 


\section{VERSION AUTEUR}

that the target utterance (italicized) would be understood, by a naïve reader, as an ironic comment.

For each story, blanks were added. You can add information in any blank or blanks if you think that this information would induce a total ironic understanding of the italicized target utterance.

You will start by 2 trainings after which you will be free to ask me questions. Afterward, the task will begin."

The sincere instruction was presented as follows: "You will see some stories. A minimal context (in bold) is provided to the situation in which the target utterance (italicized) was made. You have to add some information to the context in which way that the target utterance (italicized) would be understood, by a naïve reader, as a sincere comment.

For each story, blanks were added. You can add information in any blank or blanks if you think that this information would induce a total sincere understanding of the italicized target utterance.

You will start by 2 trainings after which you will be free to ask me questions. Afterward, the task will begin."

Once participants had read the instructions, an oral explanation of the task was given. It was specified to the participants that they could not fill the blanks with dialogues or speaking about themselves (e.g., using pronouns "I" or "we"). It was explained that blanks had to be filled with contextual information about the situation, their character listener and/or added characters.

\section{Results}

Some productions were excluded for non-compliance with the instructions (e.g., due to using quoted sentences, using multiple-line dialogues, speaking about themselves, or using inappropriate language). Seven participants ( 2 men, 5 women) were excluded due to a rate of $50 \%$ or more of their production excluded. When considering the stories ending with a given target utterance if there was too great a difference between the number of stories inducing an ironic interpretation and the number inducing a sincere interpretation, then all the stories containing that target utterance were excluded. Thus, the participations of 52 participants were conserved (28 in the ironic instruction, 24 in the sincere instruction) leading to 1840 productions: 954 produced under the ironic instruction (464 with lexical markers and 490 
without lexical markers), 886 produced under the sincere instruction (430 with lexical markers and 456 without lexical markers) (for examples cf. figure 2).

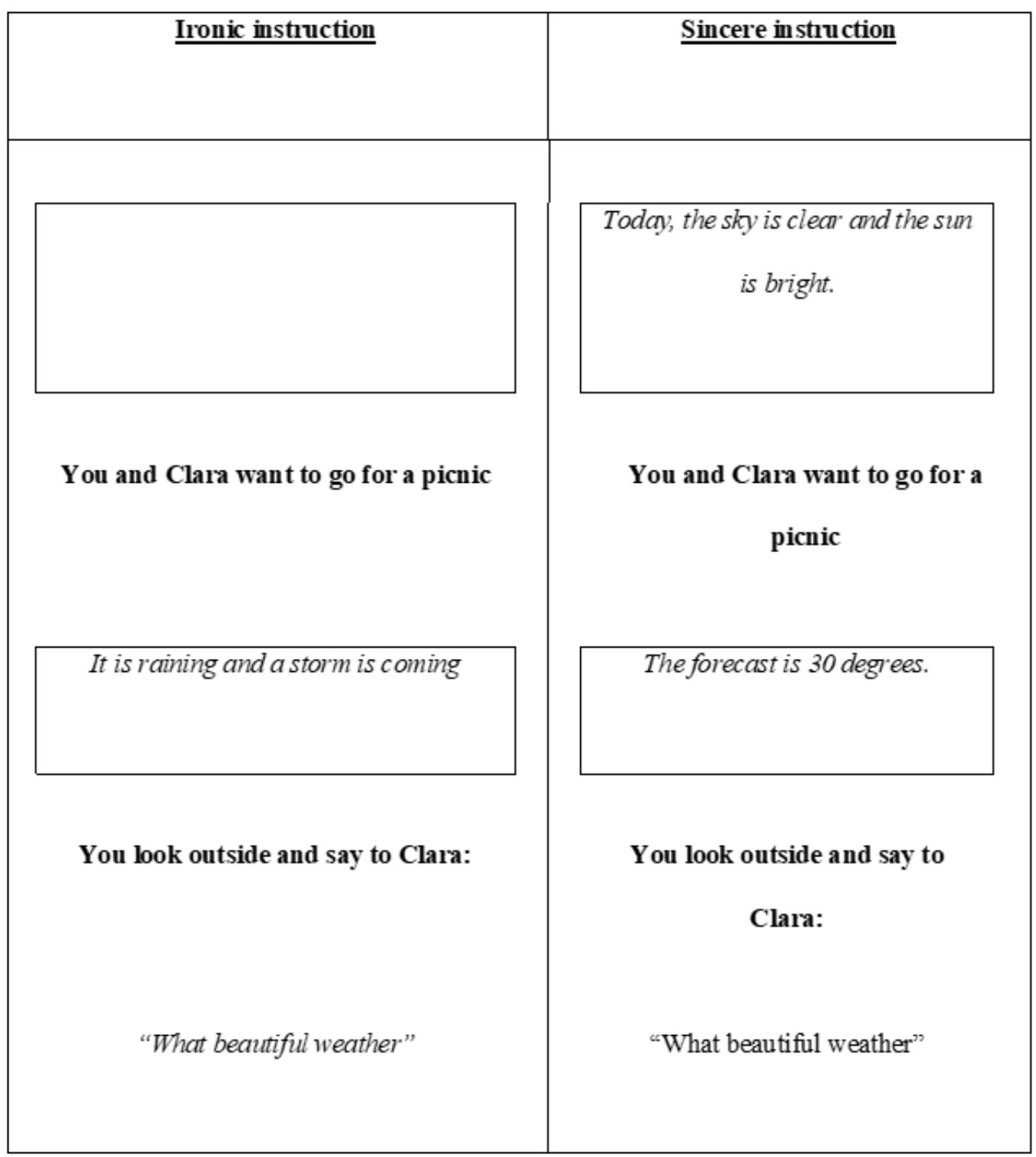

Figure 2. Example of context production according to the instruction.

\section{Step 3: Rating of the degree of irony and of the presence of the pragmatic constraints}

The first objective of this experiment was to verify whether the pragmatic constraints (i.e., allusion to a failed expectancy, negative tension and presence of a victim) were more produced in the ironic instruction than in the sincere instruction. The second aim was to evaluate the influence of the linguistic constraint (lexical marker) and the sociocultural constraint (gender) on the judgement of the degree of irony. The third aim of this experiment 


\section{VERSION AUTEUR}

was to investigate which constraints - pragmatic constraints (i.e., allusion to a failed expectancy, negative tension and presence of a victim), linguistic constraint (i.e., presence of a lexical marker) and sociocultural constraints (i.e., gender, age and level of education of the rater) - could predict an ironic interpretation of the target utterances.

\section{Participants}

Two hundred and forty-four participants (162 women and 82 men) took part in the third step as raters, none of them had participated in the previous steps of this work. They were aged 18-35 years old $(M=22.54 \pm 4.04)$ and had a level of education between 12 and 20 years $(M$ $=14.39 \pm 2.13)$. None of the raters declared any cerebral or neurologic antecedents or psychiatric disorders. All were French native speakers. They were recruited in the local community.

\section{Material, task and procedure}

The 1840 stimuli obtained in the previous experiment were divided into 122 lists of 15 or 16 stimuli. The lexical marker was a between-subject factor, meaning that half of the participants saw stimuli with lexical markers while the other half saw the stimuli without lexical markers. The participants rated an equal number of stimuli produced in the sincere instruction and stimuli produced in the ironic instruction. Stimuli with a given target utterance (e.g., "What beautiful weather") were seen once by each participant, either in the sincere production instruction or in the ironic instruction production. Participants saw only one production stimulus produced by each producer participant. Each list was randomized in two different orders creating a total of 244 booklets and allowing each complete story to be evaluated twice by two different raters. Each participant received one of the 244 booklets. Participants were asked to evaluate the level of irony of the target utterance, the presence of the pragmatic constraints allusion to a failed expectancy, negative tension, and presence of a victim on four 7-point Likert scales (1"not at all" -7 "extremely"). The general instruction was presented as follows:

"In this task, you will be asked to rate the level of irony of an utterance between inverted commas (example) taking into account the story in which the utterance is found. Then you will be asked to rate the presence, in the entire story, of factors such as: allusion to a failed expectancy, negative tension and presence of a victim. To do 
so, you will select a number from 1 (not at all) to 7 (extremely). You will be allowed to use intermediary numbers to nuance your answer."

A rating guide, containing an example and definitions of the three pragmatic constraints, was given to the participants after the general instruction and remained available throughout the entire test (cf., annex 2).

Each page of the booklet contained firstly a complete story and then the four questions which participants had to answer on 7-point Likert scales:

1. Is the target utterance in inverted commas ironic?

2. Does the target utterance in inverted commas make an allusion to a failed expectancy, prediction, preference or norm?

3. Does the above story contain negative tension?

4. Does the above story include a victim?

The test was displayed online by https://www.sondageonline.fr/

\section{Results}

Impact of the production instruction (i.e., ironic or sincere) on the perception of the pragmatic constraints (i.e., allusion to a failed expectancy, negative tension and presence of a victim)

To investigate whether the pragmatic constraints (i.e. allusion to a failed expectancy, negative tension and presence of a victim) were more produced in the ironic production instruction than in the sincere production instruction, paired samples t-tests were performed. ${ }^{1}$ The alpha level was set at $p<0.05$ for all the analyses. The results showed that the presence of each constraint (allusion to a failed expectancy $(t(243)=30.88 ; p<.001)$; negative tension $(t(243)=29.48 ; p<.001)$; presence of a victim $(t(243)=31.66 ; p<.001))$ was significantly different in the ironic production instruction and the sincere production instruction. Indeed, the pragmatic constraints were judged as more present in the context produced under the ironic production instruction (allusion to a failed expectancy $(M=4.14 \pm 1.17)$, negative tension $(M=3.79 \pm 1.17)$, presence of a victim $(M=4.07 \pm 1.11))$ than in context produced

\footnotetext{
1 Each stimulus was rated by two different participants. To assess the influence of the raters, repeated measures ANOVAs 2 production instructions (ironic, sincere) x 2 rater (number 1, number 2) were performed on the judgment of the three pragmatic constraints. Since results from these ANOVAs showed no main effect of the rater or interaction with this factor, this factor was removed from the analyses. For more clarity, we only present results from the paired samples t-tests comparing the presence of the pragmatics constraints (i.e. allusion to a failed expectancy, negative tension and presence of a victim) in each of the production instructions (ironic, sincere).
} 
under the sincere production instruction (allusion to a failed expectancy $(M=1.75 \pm 0.73$ ), negative tension $(M=1.61 \pm 0.58)$, presence of a victim $(M=1.75 \pm 0.84))$.

\section{Influence of the linguistic constraint (lexical marker) and the sociocultural constraint} (gender) on the perception of irony.

To evaluate the influence of the linguistic constraint and the sociocultural constraints on the degree of irony, a repeated measures ANOVA 2 production instructions (ironic, sincere) x 2 gender of the rater (female, male) x 2 lexical marker condition (absent, present) was performed on the level of irony ${ }^{23}$. Measures of effect size were calculated for each effect of interest by providing the partial eta-squared for ANOVAs.

The results showed a main effect of the production instructions $(F(1,240)=2451.58 ; p<$ $\left..001 ; \eta p^{2}=0.911\right)$, target utterances being judged more ironic when they were embedded in a context produced under the ironic production instruction $(M=5.85 \pm 0.85)$ than when embedded in a context, produced under the sincere production instruction $(M=1,86 \pm 0.77)$. There was no main effect of the lexical marker $\left(F(1,240)=0.39 ; p=.535 ; \eta_{p}{ }^{2}=0.002\right)$ or main effect of the gender of the rater $\left(F(1,240)=0.98 ; p=.325 ; \eta_{p}{ }^{2}=0.004\right)$. The interaction production instruction $\mathrm{x}$ gender of the raters $\mathrm{x}$ lexical marker condition was also significant $\left(F(1,240)=4.36 ; p=.038 ; \eta_{p}{ }^{2}=0.018\right)$. Pairwise comparisons showed that in the ironic production instruction, when the lexical marker was absent, female raters judged the target utterances as more ironic $(M=6.08 \pm 0.72)$ than men did $(M=5.63 \pm 0.83)(p=.003)$. Such a difference did not exist when the lexical marker was present $(p=.960)$ (cf. Figure 3) and did not exist in the sincere production instruction regardless of the lexical marker (with lexical marker $(p=.824)$; without lexical marker $(p=.175))$.

\footnotetext{
2 Each stimulus was rated by two different participants. To assess the influence of the raters, a repeated measures ANOVA 2 production instructions (ironic, sincere) x 2 gender of the rater (female, male) x 2 lexical marker condition (absent, present) x 2 rater (number 1, number 2) was performed on the level of irony. Since results from this ANOVA showed no main effect of the rater or interaction with this factor, we removed this factor from the analyses and did not present the results.

${ }^{3}$ Additional analyses including the gender of the interlocutor presented in the stimuli in the ANOVA showed no influence of this factor on the degree of the irony rating (no main effect or interaction with this factor).
} 


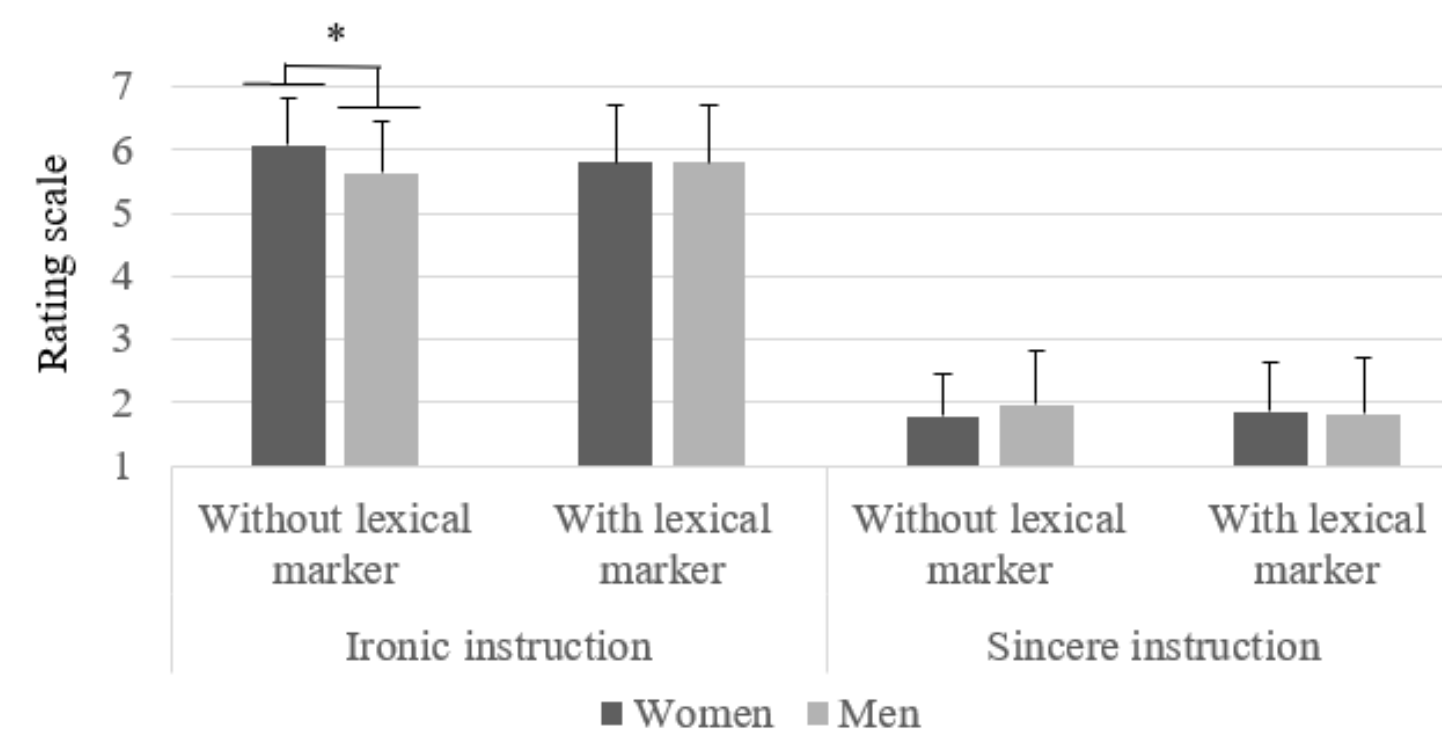

Figure 3. Level of irony according to the gender of the rater and the lexical marker in the ironic production instruction

Legend: $*=p<0.05$

The interactions production instruction $\mathrm{x}$ lexical marker condition $(F(1,240)=0.01 ; p=$

$\left..917 ; \eta_{p}^{2}<0.001\right)$ and gender of the rater $\mathrm{x}$ lexical marker condition $(F(1,240)=0.49 ; p=$ $.486 ; \eta_{p}^{2}=0.002$ ) were not significant.

Pragmatics constraints (allusion to a failed expectancy, negative tension and presence of a victim), linguistic constraint (lexical marker) and sociocultural constraints (gender, level of education and age) as potential predictors of irony perception.

To investigate which constraints - pragmatic constraints (i.e., allusion to a failed expectancy, negative tension and presence of a victim), linguistic constraint (i.e., presence of a lexical marker) and sociocultural constraints (i.e., gender, age and level of education of the rater) might account for an interpretation of the target utterances as ironic, a stepwise multiple linear regression analysis was conducted. The pragmatic constraints allusion to a failed expectancy, negative tension and presence of a victim (rating scores), the linguistic constraint lexical marker (coded 1 = present, 2 = absent) and the sociocultural constraint gender (coded as 1 = female, 2 = male), age and level of education of the rater (coded in years) were included as potential predictors and entered step by step to determine the independent predictors of the degree of irony. Firstly, Pearson correlation analyses were conducted 


\section{VERSION AUTEUR}

between the level of irony and each constraint. Correlations between the degree of irony and the pragmatic constraints were significant: allusion to a failed expectancy $(r=0.829 ; p<$ $.001)$, negative tension $(r=0.809 ; p<.001)$, presence of a victim $(r=0.808 ; p<.001)$. The correlation analyses showed that the more each of the pragmatic constraints was present, the more the target utterances were judged as ironic. The correlation analyses between the level of irony and the other constraints were not significant: presence of lexical marker $(r=0.013$; $p=.391)$, age of the rater $(r=0.008 ; p=.434)$, level of education of the rater $(r=-0.010 ; p=$ $.414)$, gender of the rater $(r=-0.016 ; p=.362)$.

The regression analysis produced five significant models. The most adjusted model $(F(5$, $482)=293.97 ; p<.001)$ accounted for $75 \%$ of the variance. It included allusion to a failed expectancy $\left(\beta^{4}=0.373 ; t=7.429 ; p<.001\right)$, presence of a victim $(\beta=0.346 ; t=8.062 ; p<$ $.001)$, negative tension $(\beta=0.203 ; t=4.002 ; p<.001)$, gender $(\beta=-0.64 ; t=-2.772 ; p=$ $.006)$ and level of education of the rater $(\beta=0.58 ; t=2.517 p=.012)$ as predictors. The linguistic constraint lexical marker $(\beta=0.013 ; t=0.559 ; p=.576)$ and the sociocultural constraint age of the rater $(\beta=-0.037 ; t=-1.117 ; p=.265)$ were not significant predictors of the variance. Thus, we found that the perception of a target utterance as ironic was predicted by each of the 3 pragmatic constraints and two out of three of the sociocultural constraints: gender of the rater and level of education. The regression analysis showed that the more the three pragmatic constraints were present, the higher the judged level of irony. In the model, the allusion to a failed expectancy was the most significant predictor accounting for $68.7 \%^{5}$ of the variance, with the presence of a victim at $5.1 \%$ and the negative tension at $0.9 \%$. The gender and the level of education of the rater were weaker but still accounted each for $0.3 \%$ of the variance. The regression analysis put forward that a woman as rater tended to predict irony judgment more than a man as rater. It also revealed that a high level of education is a better predictor of irony judgment than a low level of education.

To sum up, these results showed that when target utterances were embedded in contexts produced under the ironic production instruction, they were judged as more ironic than the ones embedded in contexts produced under the sincere production instruction. The pragmatic constraints were also judged as more present in the ironic production instruction than in the sincere production instruction. We also found that all the pragmatic constraints accounted for

\footnotetext{
${ }^{4}$ Standardized coefficient Beta: change in standard deviation for the dependant variable (i.e., level of irony) for the increase of 1 standard deviation of the independent variable (e.g., allusion to a failed expectancy) when all the other values are stable.

${ }^{5}$ Based on le R2 change
} 


\section{VERSION AUTEUR}

irony judgement with allusion to a failed expectancy being the strongest predictor. The presence of a lexical marker in the target utterance had no impact on and was not a predictor of irony rating. However, the gender of the rater was found to influence irony judgement when the utterance to be judged did not contain a lexical marker. This sociocultural constraint, just as the level of education of the rater, also predicted irony judgement.

\section{Discussion}

The objective of the present study was to investigate in French which constraints - pragmatic (allusion to a failed expectancy, negative tension and presence of a victim), linguistic (lexical marker) and sociocultural (gender, age and level of education of the rater) - or combination of constraints would be the best predictors of irony perception.

The main results revealed that amongst the constraints investigated in the present study all the pragmatic constraints and two of the sociocultural constraints (i.e., gender and level of education of the rater) accounted for irony perception. These five constraints explained the variance at the substantial level of $75 \%$. These results disclosed evidence of the sufficiency of these five constraints to lead to an ironic interpretation, but they did not allow us to make a conclusion about their necessity. The three pragmatic constraints investigated (allusion to a failed expectancy, negative tension and presence of a victim) - which were more present in context produced under the ironic production instruction than in context produced under the sincere one - were found to be the strongest predictors of irony perception, and specifically allusion to a failed expectancy, which appeared to be the strongest. Such results confirmed the main role of context put forward in the literature (Gibbs, 1986) and particularly the essential role of the allusion to a failed expectancy in irony perception previously highlighted in the literature (Campbell \& Katz, 2012; Colston, 2000; Gerrig \& Goldvarg, 2000). Differently, Campbell \& Katz (2012) have found that allusion to a failed expectancy plays a minimal role in sarcasm perception, explaining only $4.7 \%$ of the variance, when in our experiment it explains $68.7 \%$ of irony perception. A main difference also appears in the role played by negative tension, explaining $61.4 \%$ of their variance and only $0.9 \%$ of ours. Such differences could be explained by the type of context produced in these studies. Indeed, we asked our participants to create contexts leading to an ironic interpretation of the target utterances, while Campbell \& Katz (2012) focused on sarcastic interpretation. Since sarcasm is characterized by the expression of a negative and critical attitude concerning a victim or a 


\section{VERSION AUTEUR}

group of victims (Lee and Katz, 1998), the finding that negative tension would be more constraining for sarcasm interpretation than for irony interpretation is relevant. These different results may also be explained by the perspective of the participants. In our experiment, participants were in speaker perspective in the ironic utterance while they were in a third person perspective in the experiment of Campbell \& Katz (2012). As a speaker in our experiment, it may be possible that the participants felt more comfortable to express irony via the allusion to a failed expectancy than via a negative feeling such as negative tension. For participants in the Campbell \& Katz (2012) study, the third person perspective may not generate the same behavior. Pexman \& Olineck (2002) showed that when participants in third person perspective judged the attitude of a speaker of an ironic utterance, they tended to judge the speaker more mocking than when the utterance was sincere. Additionally, Bryant (2012) suggested that the scalar evaluative gap between what is said and what it is meant (i.e., allusion to a failed expectancy) has to be recognized to distinguish irony, which requires inferring the mental state of the speaker. Thus, the evaluation of irony starting with an egocentric perspective (Akimoto et al., 2012; Deliens et al., 2017; Epley, Keysar, Van Boven, \& Gilovich, 2004) may explain why allusion to a failed expectancy played a larger role in our study, where participants were in a speaker perspective.

Even if pragmatic constraints - characteristics of context - were the strongest, two sociocultural constraints, gender and level of education, were also, even at a low level, predictors of ironic interpretation. The emergence of gender as a predictor of irony perception confirmed our result about women being more sensitive to irony. Indeed, we showed that when the ironic utterances - embedded in a context produced under the ironic production instruction - did not contain a lexical marker, women judged the target utterances as more ironic than men did. These results support Holtgraves (1991) who showed that women are more likely to interpret a statement as indirect than men. That women are more sensitive to irony can be explained by the presence of a negative tension in irony (Campbell \& Katz, 2012; Utsumi, 2000). Since women recognize emotions better and more rapidly than men, particularly negative ones such as anger (see Christov-Moore et al., 2014 for a review), they could be more sensitive to the negative tension conveyed by irony. This hypothesis is congruent with women judging ironic utterances to be more negative (Gucman, 2016) and meaner (Glenwright, Tapley, Rano, \& Pexman, 2017) than when judged by men. Our study did not allow us to explore the influence of the producers' gender. Previous studies on the gender of producers have highlighted various results, some showing no impact of gender (Bowes \& Katz, 2011; Colston \& Lee, 2004; Dress et al., 2008) while others showing that 
men produce sarcasm more often than women (Gibbs, 2000; Rockwell \& Theriot, 2001). While these results are not incompatible with the results of the gender of the producers, our results pointed out a discrepancy between production and judgment tasks.

A higher level of education seemed to facilitate the irony processing, reinforcing what was put forward concerning metaphor processing by older adults (Champagne et al., 2006; Champagne-Lavau, Monetta, et al., 2012). It should be noted that all our participants had a minimum level of education of 12 years. It could be interesting to investigate the role of the level of education as predictor with a larger range integrating lower level of education. Even if the study of sociocultural constraints has experienced a considerable rise, several studies still focused on context and ironic utterances features. The gender and the level of education of the rater appearing as predictors of irony perception, our results clearly suggest that these factors are worthy of specific attention when studying irony perception.

Two of the investigated constraints, sociocultural (age) and linguistic (lexical marker) did not appear to be sufficient constraints since they were not predictors of irony perception. It is known that the ability to perceive irony changes over time (Glenwright et al., 2017), here the age of the participants was not a predictor of irony perception but the age range was limited. Further experiments integrating children and older adults are needed to fully explore the role of age in irony perception. Confirming the results of Kreuz \& Caucci (2007) but not those of Kunneman et al., (2015), the presence of a lexical marker did not appear to be a predictor of irony perception. The explanation can probably be found in the origin of the data. Kreuz \& Caucci (2007) extracted their items from the Google Book Corpus while those of Kunneman et al., (2015) come from a very specific source. Indeed, Kunneman et al., (2015) extracted their items from Twitter. The messages on Twitter have specific communicative goals and were limited to 140 characters maximum. Such specific data may explain the difference with our results and those of Kreuz \& Caucci (2007). The fact that the presence of a lexical marker was not a predictor of irony perception supports Attardo (2000) who said that lexical markers are not factors of irony, and that meaning is not necessary to an utterance for it to be understood as ironic. According to Attardo et al., (2003) and Utsumi (2000), a lexical marker is a cue of irony that makes it more easily perceived. However, the presence of a lexical marker did not seem to facilitate the irony perception by alerting that the utterance was ironic. Our result also supports the work of Burgers et al., (2012) who showed that presence of one lexical marker in the utterance did not facilitate irony comprehension. Nevertheless, they found such facilitating effect when the ironic utterance contained three lexical markers. The absence of lexical markers as predictors of irony interpretation fit the Constraints Satisfaction 


\section{VERSION AUTEUR}

hypothesis in which none of the constraints are necessary. Indeed, some constraints such as lexical markers could be a so weak constriction that their absence would not be followed by a disappearance of irony perception. Moreover, even if a constraint such as lexical markers is not a predictor and had no direct influence on irony perception, it seems to play a role by having an influence on the other predictors like gender since a difference between men's and women's judgements was found only when the utterances did not contain a lexical marker. Our work was on French language and the studies we are looking at were done on Dutch (Burgers et al., 2012; Kunneman et al., 2015) or on English (Attardo et al., 2003; Hancock, 2004; Kreuz \& Caucci, 2007), it may also be possible then that the influence of the lexical marker differs according to this dimension. One might argue that to use the same target utterance with and without the lexical marker would have been a better procedure to manipulate the presence of the constraint lexical marker. However, as participants saw both conditions (i.e., with and without a lexical marker) in the task on the context production, they would have been able to compare the conditions. Thus, using such a procedure might have led to a bias: participants would have been likely to adopt a specific pattern of context production for each condition (i.e., with and without a lexical marker).

As allowed by Constraints Satisfaction approach, our study confirmed the constricting role played by constraints from various sources (pragmatic, linguistic and sociocultural). Several studies have suggested that the constraints from these different sources are processed early on and in parallel (Akimoto et al., 2012; A. Katz et al., 2001; Pexman et al., 2000; Spotorno \& Noveck, 2014) in irony processing. An online study would be necessary to evaluate the temporality of the influence of our investigated constraints. Moreover, we selected the studied constraints based on the previous literature and our most efficient combination of constraints (allusion to a failed expectancy, presence of a victim, negative tension, gender and level of education of the raters) explained the variance at the substantial level of $75 \%$. We may consider that other constraints such as prosody and gender of the interlocutor for example could account for the missing $25 \%$. Thus, further research is required to explore whether such other possible constraints could invite an ironic meaning.

To conclude, this study in French showed for the first time that a combination of pragmatic constraints (i.e., allusion to a failed expectancy, presence of a victim, negative tension) and sociocultural constraints such as gender and level of education of the participants judging irony best predicts the interpretation of utterances as ironic. More precisely, the pragmatic constraint of allusion to a failed expectancy was the strongest predictor, while gender and level of education accounted for irony perception to a lesser 


\section{VERSION AUTEUR}

extent. Accordingly, it seems essential that future research on irony perception should no longer neglect these types of constraints. 
VERSION AUTEUR

\section{References}

Akimoto, Y., Miyazawa, S., \& Muramoto, T. (2012). Comprehension Processes of Verbal Irony: The Effects of Salience, Egocentric Context, and Allocentric Theory of Mind. Metaphor and Symbol, 27(3), 217-242.

Attardo, S. (2000). Irony markers and functions: Towards a goal-oriented theory of irony and its processing. Rask, 12, 3-20.

Attardo, S., Eisterhold, J., Hay, J., \& Poggi, I. (2003). Multimodal markers of irony and sarcasm. Humor - International Journal of Humor Research, 16(2).

Bowes, A., \& Katz, A. (2011). When Sarcasm Stings. Discourse Processes, 48(4), 215-236.

Bryant, G. A. (2012). Is Verbal Irony Special?: Is Verbal Irony Special? Language and Linguistics Compass, 6(11), 673-685.

Burgers, C., van Mulken, M., \& Schellens, P. J. (2012). Type of evaluation and marking of irony: The role of perceived complexity and comprehension. Journal of Pragmatics, 44(3), 231-242.

Campbell, J. D., \& Katz, A. N. (2012). Are there necessary conditions for inducing a sense of sarcastic irony? Discourse Processes, 49:6, 459-480.

Champagne, M., Jean-Louis, S., \& Joanette, Y. (2006). Effet du vieillissement sur le traitement du langage non-littéral. Canadian Journal on Aging / La Revue canadienne du vieillissement, 25(1), 55-64.

Champagne-Lavau, M., Charest, A., Anselmo, K., Rodriguez, J.-P., \& Blouin, G. (2012). Theory of mind and context processing in schizophrenia: The role of cognitive flexibility. Psychiatry Research, 200, 184-192.

Champagne-Lavau, M., Cordonier, N., Bellmann, A., \& Fossard, M. (2018). Context processing during irony comprehension in right-frontal brain-damaged individuals. Clinical Linguistics \& Phonetics, 32(8), 721-738.

Champagne-Lavau, M., Monetta, L., \& Moreau, N. (2012). Impact of educational level on metaphor processing in older adults. Revue Française de Linguistique Appliquée, 17, 89-100.

Cheang, H. S., \& Pell, M. D. (2011). Recognizing sarcasm without language: A crosslinguistic study of English and Cantonese. Pragmatics \& Cognition, 19(2), 203-223.

Christov-Moore, L., Simpson, E. A., Coudé, G., Grigaityte, K., Iacoboni, M., \& Ferrari, P. F. (2014). Empathy: Gender effects in brain and behavior. Neuroscience \& Biobehavioral Reviews, 46, 604-627. 
VERSION AUTEUR

Colston, H. L. (2000). On necessary conditions for verbal irony comprehension. Pragmatics and Cognition, 8, 277-324.

Colston, H., L. (2002). Contrast and assimilation in verbal irony. Journal of Pragmatics, 34, $111-142$.

Colston, H. L. (2005). Social and Cultural Influences on Figurative and Indirect Language. In Figurative language comprehension: Social and cultural influences (N.J: Lawrence Erlbaum Associates, pp. 99-130). Mahwah: Colston, H. L., \& Katz, A. N.

Colston, H. L., \& Gibbs, R. W. (2002). Are Irony and Metaphor Understood Differently? Metaphor and Symbol, 17(1), 57-80.

Colston, H. L., \& Lee, S. Y. (2004). Gender differences in verbal irony use. Metaphor and Symbol, 19(4), 289-306.

Colston, H., L., \& O'Brien, J. (2000). Contrast and pragmatics in figurative language: Anything understatement can do, irony can do better. Journal of Pragmatics, 32, $1557-1583$.

Colston, H. L., \& O’Brien, J. (2000). Contrast of Kind Versus Contrast of Magnitude: The Pragmatic Accomplishments of Irony and Hyperbole. Discourse Processes, 30(2), 179-199.

Deliens, G., Antoniou, K., Clin, E., \& Kissine, M. (2017). Perspective-taking and frugal strategies: Evidence from sarcasm detection. Journal of Pragmatics, 119, 33-45.

Deliens, G., Antoniou, K., Clin, E., Ostashchenko, E., \& Kissine, M. (2018). Context, facial expression and prosody in irony processing. Journal of Memory and Language, 99, $35-48$.

Dews, S., \& Winner, E. (1999). Obligatory processing of literal and nonliteral meanings in verbal irony. Journal of Pragmatics, 31(12), 1579-1599.

Dress, M. L., Kreuz, R. J., Link, K. E., \& Caucci, G. M. (2008). Regional Variation in the Use of Sarcasm. Journal of Language and Social Psychology, 27(1), 71-85.

Epley, N., Keysar, B., Van Boven, L., \& Gilovich, T. (2004). Perspective Taking as Egocentric Anchoring and Adjustment. Journal of Personality and Social Psychology, $87(3), 327-339$.

Gerrig, R. J., \& Goldvarg, Y. (2000). Additive effects in the perception of sarcasm: situational disparity and echoic mention. Methaphor and Symbol, 15(4), 197-208.

Gibbs, R. W. Jr. (1986). On the psycholinguistics of sarcasm. Journal of Experimental Psychology: General, 115, 3-15.

Gibbs, R. W. Jr. (2000). Irony in talk among friends. Metaphor and Symbol, 15, 5-27. 
Gibbs, R. W. Jr. (2001). Evaluating Contemporary Models of Figurative Language Understanding. Metaphor and Symbol, 17.

Giora, R., \& Fein, O. (1999). Irony : context and sailence. Metaphor and Symbol, 14, 241257.

Glenwright, M., Tapley, B., Rano, J. K. S., \& Pexman, P. M. (2017). Developing Appreciation for Sarcasm and Sarcastic Gossip: It Depends on Perspective. Journal of Speech Language and Hearing Research, 60(11), 3295-3309.

Grice, H. P. (1975). Logic and Conversation. In Syntax and semantics: Vol. 3. Speech acts (P. Cole \& J. L. Morgan, pp. 41-58). New-York: Academic.

Gucman, M. (2016). The Role of Individual Differences and Situational Factors in Perception of Verbal Irony. Psychology of Language and Communication, 20(3), 255-277.

Gudykunst, W. B., Yoon, Y., \& Nishida, T. (1987). The influence of individualism-collectivism on perceptions of communication in ingroup and outgroup relationships. Communication Monographs, 54(3), 295-306.

Hancock, J. T. (2004). Verbal Irony Use in Face-To-Face and Computer-Mediated Conversations. Journal of Language and Social Psychology, 23(4), 447-463.

Holtgraves, T. (1991). Interpreting Questions and Replies: Effects of Face-Threat, Question Form, and Gender. Social Psychology Quarterly, 54(1), 15-24.

Holtgraves, T. (1994). Communication in Context: Effects of Speaker Status on the Comprehension of Indirect Requests. Journal of Experimental Psychology: Learning, Memory and Cognition, 20(15), 1205-1218.

Holtgraves, T. (1997a). Politeness and memory for the wording of remarks. Memory \& Cognition, 25(1), 106-116.

Holtgraves, T. (1997b). Styles of language use: Individual and cultural variability in conversational indirectness. Journal of Personality and Social Psychology, 73(3), $624-637$.

Holtgraves, T., \& Yang, J.-N. (1992). The interpersonal underpinnings of request strategies: general principles and differences due to culture and gender. Journal of Personality and Social Psychology, 62, 246-256.

Ivanko, S. L., \& Pexman, P. M. (2003). Context incongruity and irony processing. Discourse Processes, 35(3), 241-279.

Katz, A. N., \& Ferretti, T. R. (2001). Moment-by-moment reading of proverbs in literal and nonliteral contexts. Metaphor and Symbol, 16(3-4), 193-221. 
Katz, A. N., \& Pexman, P. M. (1997). Interpreting figurative statements: speaker occupation can change metaphor to irony. Metaphor and Symbol, 12(1), 19-41.

Katz, A., Piasecka, I., \& Toplak, M. (2001, November). Comprehending the sarcastic comments of males and females. Poster presented at the 42nd annual meeting of the Psychonomic Society, Orlando, FL.

Kreuz, R. J., \& Caucci, G. M. (2007). Lexical influences on the perception of sarcasm. 1-4.

Kreuz, R. J., \& Glucksberg, S. (1989). How to be sarcastic: The echoic reminder theory of verbal irony. Journal of Experimental Psychology: General, 118(4), 374-386.

Kumon-Nakamura, S., Glucksberg, S., \& Brown, M. (1995). How about another piece of pie : the allusional pretense theory of discourse irony. Journal of Experimental Psychology: General, 124(1), 3-21.

Kunneman, F., Liebrecht, C., van Mulken, M., \& van den Bosch, A. (2015). Signaling sarcasm: From hyperbole to hashtag. Information Processing \& Management, 51(4), $500-509$.

Lee, C. J., \& Katz, A. N. (1998). The Differential Role of Ridicule in Sarcasm and Irony. Metaphor and Symbol, 13(1), 1-15.

Milanowicz, A. (2013). Irony as a Means of Perception Through Communication Channels. Emotions, Attitude and IQ Related to Irony Across Gender. Psychology of Language and Communication, 17(2), 115-132.

Pexman, P. M. (2008). It's Fascinating Research: The Cognition of Verbal Irony. Current Directions in Psychological Science, 17(4), 286-290.

Pexman, P. M., Ferretti, T. R., \& Katz, A. N. (2000). Discourse Factors That Influence Online Reading of Metaphor and Irony. Discourse Processes, 29(3),

Pexman, P. M., \& Olineck, K. M. (2002). Does Sarcasm Always Sting? Investigating the Impact of Ironic Insults and Ironic Compliments. Discourse Processes, 33(3), 199217.

Rivière, E., Klein, M., \& Champagne-Lavau, M. (2018). Using context and prosody in irony understanding: Variability amongst individuals. Journal of Pragmatics, 138, 165-172.

Rockwell, P., \& Theriot, E. M. (2001). Culture, gender, and gender mix in encoders of sarcasm: A self-assessment analysis. Communication Research Reports, 18(1), 44-52.

Scharrer, L., \& Christmann, U. (2011). Voice Modulations in German Ironic Speech. Language and Speech, 54(4), 435-465.

Searle, J. R. (1978). Literal meaning. Erkenntnis, 13, 207-224. 


\section{VERSION AUTEUR}

Spotorno, N., \& Noveck, I. A. (2014). When is irony effortful? Journal of Experimental Psychology: General, 143(4), 1649-1665.

Triandis, H. C., Bontempo, R., Villareal, M. J., Asai, M., \& Lucca, N. (1988). Individualism and collectivism: Cross-cultural perspectives on self-ingroup relationships. Journal of Personality and Social Psychology, 54(2), 323-338.

Utsumi, A. (2000). Verbal irony as implicit display of ironic environment: distinguishing ironic utterances from nonirony. Journal of Pragmatics, 32, 1777-1806.

Voyer, D., Thibodeau, S.-H., \& Delong, B. J. (2014). Context, Contrast, and Tone of Voice in Auditory Sarcasm Perception. Journal of Psycholinguistic Research, 45(1), 29-53.

Woodland, J., \& Voyer, D. (2011). Context and intonation in the perception of sarcasm. Metaphor and Symbol, 26, 227-239. 


\section{VERSION AUTEUR}

\section{Appendix}

1. selected target utterances.

\begin{tabular}{|c|c|}
\hline Target utterance & Lexical marker \\
\hline $\begin{array}{l}\text { Tu es extrêmement généreuse } \\
\text { [You are extremely generous] }\end{array}$ & with \\
\hline $\begin{array}{l}\text { Tu es vraiment talentueuse } \\
\text { [You are really talented] }\end{array}$ & with \\
\hline $\begin{array}{l}\text { Tu es vraiment mélomane } \\
\text { [You really are a music lover] }\end{array}$ & with \\
\hline $\begin{array}{l}\text { Tu es tellement cultivée } \\
\text { [You are so cultured] }\end{array}$ & with \\
\hline $\begin{array}{l}\text { Tu es vraiment une amie attentionnée } \\
\text { [You really are a caring friend] }\end{array}$ & with \\
\hline $\begin{array}{l}\text { Tu es un coureur extrêment rapide } \\
\text { [You are an extremely fast runner] }\end{array}$ & with \\
\hline $\begin{array}{l}\text { Tu m'as totalement convaincu } \\
\text { [You totally convinced me] }\end{array}$ & with \\
\hline $\begin{array}{l}\text { Tu es vraiment drôle } \\
\text { [You are very funny] }\end{array}$ & with \\
\hline $\begin{array}{l}\text { Tu es vraiment habile } \\
\text { [You are really good] }\end{array}$ & with \\
\hline $\begin{array}{l}\text { Tu es vraiment patient } \\
\text { [You are really patient] }\end{array}$ & with \\
\hline $\begin{array}{l}\text { Tu as une mémoire phénoménale } \\
\text { [You have a phenomenal memory] }\end{array}$ & without \\
\hline $\begin{array}{l}\text { Tu es une danseuse gracieuse } \\
\text { [You are a graceful dancer] }\end{array}$ & without \\
\hline $\begin{array}{l}\text { Tu es une oratrice intéressante } \\
\text { [You are an interesting speaker] }\end{array}$ & without \\
\hline $\begin{array}{l}\text { Tu es une guitariste remarquable } \\
\text { [You are a remarkable guitarist] }\end{array}$ & without \\
\hline $\begin{array}{l}\text { Tu es d'une grande aide } \\
\text { [You are a big help] }\end{array}$ & without \\
\hline
\end{tabular}




\begin{tabular}{|c|c|}
\hline $\begin{array}{l}\text { Tu es un chanteur merveilleux } \\
\text { [You are a wonderful singer] }\end{array}$ & without \\
\hline $\begin{array}{l}\text { Tu es un bon conducteur } \\
\text { [You are a good driver] }\end{array}$ & without \\
\hline $\begin{array}{l}\text { Tu es bavard } \\
\text { [You are talkative] }\end{array}$ & without \\
\hline $\begin{array}{l}\text { Tu es un génie de l'informatique } \\
\text { [You are a computer genius] }\end{array}$ & without \\
\hline $\begin{array}{l}\text { Tu travailles dur } \\
\text { [You work hard] }\end{array}$ & without \\
\hline $\begin{array}{l}\text { Quel temps splendide } \\
\text { [What splendid weather] }\end{array}$ & with \\
\hline $\begin{array}{l}\text { Que c'est beau } \\
\text { [How beautiful] }\end{array}$ & with \\
\hline $\begin{array}{l}\text { Que c'est simple } \\
\text { [How simple] }\end{array}$ & with \\
\hline $\begin{array}{l}\text { Que c'est propre } \\
\text { [How tidy] }\end{array}$ & with \\
\hline $\begin{array}{l}\text { Qu'il fait bon } \\
\text { [It is so warm] }\end{array}$ & with \\
\hline $\begin{array}{l}\text { Quel monde } \\
\text { [What a crowd] }\end{array}$ & with \\
\hline $\begin{array}{l}\text { Quel choix } \\
\text { [What a choice] }\end{array}$ & with \\
\hline $\begin{array}{l}\text { Quel livre passionnant } \\
\text { [What an exciting book] }\end{array}$ & with \\
\hline $\begin{array}{l}\text { Quelle histoire extraordinaire } \\
\text { [What an extraordinary story] }\end{array}$ & with \\
\hline $\begin{array}{l}\text { Quelle chance } \\
\text { [How lucky] }\end{array}$ & \begin{tabular}{|l|} 
with \\
\end{tabular} \\
\hline $\begin{array}{l}\text { C'est genial } \\
\text { [It's awesome] }\end{array}$ & without \\
\hline $\begin{array}{l}\text { C'est solide } \\
\text { [It's solid] }\end{array}$ & without \\
\hline C'est pratique & without \\
\hline
\end{tabular}


VERSION AUTEUR

\begin{tabular}{|l|l|}
\hline$[$ It's convenient] & \\
\hline $\begin{array}{l}\text { C'est subtile } \\
\text { [It's subtle }]\end{array}$ & without \\
\hline $\begin{array}{l}\text { C'est utile } \\
\text { [It's useful }]\end{array}$ & without \\
\hline $\begin{array}{l}\text { Ce plat est délicieux } \\
\text { [This dish is delicious }]\end{array}$ & without \\
\hline $\begin{array}{l}\text { C'est joli } \\
\text { [It's pretty }]\end{array}$ & without \\
\hline $\begin{array}{l}\text { Ça donne envie } \\
\text { [It's tempting }]\end{array}$ & without \\
\hline $\begin{array}{l}\text { C'est joyeux } \\
{[\text { It's joyful }]}\end{array}$ & without \\
\hline $\begin{array}{l}\text { C'est rapide } \\
\text { [It's fast }]\end{array}$ & without \\
\hline
\end{tabular}

\section{Rating guide}

a. French version

Lors de cette tâche, il va vous être demandé d'évaluer, en tenant compte de l'histoire dans laquelle il se trouve, le niveau d'ironie d'un énoncé entre guillemets (dans l'exemple cidessous «Quelle chambre bien rangée »). Par la suite, il vous sera demandé d'évaluer la présence, dans l'ensemble de l'histoire, d'éléments tels que : l'allusion à une attente déçue ; la tension négative ; et la présence d'une victime.

Afin de vous aider à les évaluer, voici les définitions des éléments accompagnées d'un exemple.

\section{Exemple:}

Une maman demande à son petit garçon de ranger sa chambre. Le petit garçon lit une BD et quand sa maman revient 20 min après sa chambre n'est pas rangée. 


\section{VERSION AUTEUR}

La maman dit à son fils :

"Quelle chambre bien rangée »

Allusion à une attente déçue

Faire allusion à une attente déçue est le fait de faire allusion à une attente, prédiction, préférence ou norme ayant été violées. L'allusion à une attente déçue fait référence à une différence entre une attente et la réalité.

Dans l'exemple ci-dessus, la maman avait une attente : que la chambre soit rangée. Cette attente est déçue car dans la réalité, la chambre n'est pas rangée. La maman en disant «Quelle chambre bien rangée », fait donc allusion à la déception de l'attente.

Tension négative

La tension négative est l'expression indirecte d'une attitude négative. C'est le fait d'avoir une attitude émotionnelle négative (ex. déception, colère, reproche, envie, etc.) envers l'écart entre ce qui est attendu et la réalité.

Dans l'exemple ci-dessus, la tension négative est l'expression du mécontentement de la maman face au fait que la chambre ne soit pas rangée.

Présence d'une victime

Par victime, nous entendons une ou des personnes qui serait visées, moquées, tournées en dérision et/ou qui pourrait être tenue pour responsable de la non réalisation des attentes du locuteur.

Dans l'exemple ci-dessus, la victime est le petit garçon car il est visé et peut être tenu comme responsable de la déception de l'attente de sa maman : que la chambre soit rangée. 


\section{VERSION AUTEUR}

b. English translation

In this task, you will be asked to evaluate, taking into account the story in which it is embedded, the level of irony of a quoted statement (in the example below "What a tidy room"). Afterward, you will be asked to evaluate the presence, in the whole story, of elements such as: the allusion to a failed expectancy; the negative tension; and the presence of a victim.

To help you evaluate the presence of the three elements, here are definitions of each term based on an example story.

\section{Example:}

A mother asks her little boy to tidy up his room. The boy spends his time reading a comic book, and when his mom comes back 20 minutes later his room is not tidy. The mother says to her son:

"What a tidy room."

\section{Allusion to a failed expectancy}

To allude to a failed expectancy is to allude to an expectation, prediction, preference or norm having been violated. The allusion to a failed expectancy refers to a difference between an expectation and reality.

In the example above, the mother had an expectation: that the room would be tidy when she returned. This expectation is violated when she returns, because in reality, the room is not tidy. Thus, when the mother says, "What a tidy room," she alludes to the failure of the expectation. 


\section{VERSION AUTEUR}

Negative tension

Negative tension is the indirect expression of a negative attitude. It indicates the presence of a negative emotional attitude (e.g., disappointment, anger, reproach, envy, etc.) towards the gap between what is expected and reality.

In the example above, the negative tension is the expression of the mother's dissatisfaction with the fact that the room is not tidy.

Presence of a victim

With the use of the term, 'victim', we refer a person or persons who would be targeted, mocked, ridiculed and/or who could be held responsible for the failure to fulfill the speaker's expectation.

In the example above, the victim is the little boy because he is targeted and can be held responsible for the disappointment of his mother's expectation, i.e., that the room be tidy. 